ZOOLOGIA 29 (2): 115-120, April, 2012

doi: $10.1590 /$ S1984-46702012000200003

\title{
Abundance changes and activity flexibility of the oncilla, Leopardus tigrinus (Carnivora: Felidae), appear to reflect avoidance of conflict
}

\author{
Luiz Gustavo R. Oliveira-Santos 1,6 , Maurício E. Graipel'2, Marcos A. Tortato3, \\ Carlos A. Zucco ${ }^{1}$, Nilton C. Cáceres ${ }^{4} \&$ Fernando V. B. Goulart ${ }^{5}$
}

\begin{abstract}
${ }^{1}$ Laboratório de Ecologia e Conservação de Populações, Departamento de Ecologia, Universidade Federal do Rio de Janeiro. Caixa Postal 68020, 21941-590 Rio de Janeiro, RJ, Brazil.

${ }^{2}$ Departamento de Ecologia e Zoologia, Universidade Federal de Santa Catarina. 88040-970 Florianópolis, SC, Brazil.

${ }^{3}$ Programa de Pós-graduação em Ecologia e Conservação, Setor de Ciências Biológicas, Universidade Federal do Paraná. 81531-980, Curitiba, PR, Brazil.

${ }^{4}$ Departamento de Biologia, Universidade Federal de Santa Maria. 97105-900 Santa Maria, RS, Brazil.

${ }_{5}^{5}$ Programa de Pós-graduação em Ecologia e Conservação, Universidade Federal do Mato Grosso do Sul. 79070-900 Campo Grande, MS, Brazil.

${ }_{6}^{6}$ Corresponding Author. Email: gu_tapirus@hotmail.com
\end{abstract}

\begin{abstract}
We investigated the density and activity of the oncilla, Leopardus tigrinus (Schreber, 1775), a threatened small cat, in the Brazilian Atlantic Forest, using camera-trap data. We described differences in the activity of individuals occurring alone or in sympatry with larger cats. Oncilla presented low densities (7-13 ind./100 km²) and high flexibility in its activity. The oncillas were primarily nocturnal in the absence of other larger cat species - margay, ocelot and puma - but became more diurnal, with a cathemeral activity pattern, when the other cats were present. Oncilla is likely to be in a subordinate position in interactions with larger cats and changes its activity to decrease the chances for interspecific encounters. In this study, however, the presence of other cat species covaries with habitat changes (from coastal forest patches to dense evergreen forests). We also verified the highest oncilla relative abundance in an area with no sympatric larger cats, with abundance decreasing when it was in sympatry with margay, ocelot and puma. Our results, together with recent records of oncilla in other degraded landscapes of the Atlantic Forest of Brazil, provide evidence that oncillas may thrive even in harsh environments where other cats have already been extinct. This raise interesting conservation insights, as in the absence of other cats, L. tigrinus may assume a top predator role of these impoverished vertebrate communities.
\end{abstract}

KEY WORDS. Activity pattern; camera trap; intraguild competition; little spotted cat; Neotropical felid guild.

The oncilla, Leopardus tigrinus (Schreber, 1775), is the smallest (1.5-3.0 kg) Brazilian cat, and basic ecological aspects about its abundance and present geographical range remain uncertain. Despite its reported occurrence from Costa Rica to Northern Argentina (Oliveira \& Cassaro 2005), there are few consistent records in the central and north part of South America, even with the recent and systematic efforts using camera-traps to survey mammal species in this region (SILVEIRA et al. 2003, Gómez et al. 2005). As the broad geographic range of oncilla strongly overlaps with the distribution of other felid species, there is much speculation about whether the oncilla is really absent or occurs at low densities in most of its range. In this case, the rarity of the species could be explained by competitive intraguild interactions, mainly with ocelots (OliverRA et al. 2010).
The oncilla is reported as solitary, nocturnal, and scansorial, inhabiting mainly wet and forested sites (OLIVEIRA 1994, Goulart et al. 2009). The few studies concerning its ecology have focused only on diet, which consists mainly of small rodents, birds, lizards, snakes and amphibians (Facure \& GiareTtA 1996, Wang 2002, Tortato \& Oliveira 2005).

In this study we discuss possible effects of habitat and/or intraguild interactions on the activity and abundance of oncilla. We 1) conducted the first systematic density estimation of the oncilla in the wild; 2) described the activity patterns of the species in three areas; and 3) discussed whether shifts in abundance and activity of oncillas could be triggered by the presence of larger wild cats and/or by habitat differences. We expected that oncillas would be mainly nocturnal, as reported for other Neotropical cats (Gómez et al. 2005), and that differ- 
ences in habitat and/or in cat assemblage could trigger changes in its activity and abundance.

\section{MATERIAL AND METHODS}

This study was carried out in three sites in the Southern Brazilian Atlantic Forest, state of Santa Catarina, Brazil: Maciambu Lowland (ML) $\left(27^{\circ} 50^{\prime} 500^{\prime \prime} S, 48^{\circ} 37^{\prime} 43^{\prime \prime} \mathrm{W}\right)$, in the

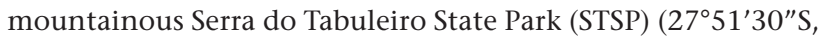
$48^{\circ} 38^{\prime} 33^{\prime \prime} \mathrm{W}$ ) and in the Caraguatá Ecological Reserve (CER) $\left(27^{\circ} 25^{\prime} 51^{\prime \prime} \mathrm{S}, 48^{\circ} 51^{\prime} 01^{\prime \prime} \mathrm{W}\right)$. At $\mathrm{ML}$, the main vegetation type is the coastal salt marsh with sparse coastal forest patches, swamps and permanent lakes. STSP and CER are located in a hills ranging from 500 to $1220 \mathrm{~m}$ above sea level and the main vegetation type is the dense evergreen Atlantic Forest with a few relict patches of the pine Araucaria angustifolia (Bertol.) Kuntze 1898 at higher altitudes. The climate is subtropical, with an annual rainfall of about $1800 \mathrm{~mm}$, and the mean temperatures ranging from 20 to $24^{\circ} \mathrm{C}$ in January, and from 12 to $16^{\circ} \mathrm{C}$ in July, in the three study areas.

Camera-traps (Tigrinus $^{\circledR}$, Santa Catarina, Brazil) were used to study the cat populations. Monitoring was conducted between January 2005 and December 2006 at ML, and between August 2004 and December 2005 at STSP and CER. Eight, 15 and 40 camera-traps were used to sample 18,18 and 29 stations at ML, STSP and CER, respectively. Cameras were active for 10, 122 and 140 days, on average, in each station (range: 8$30,53-256,28-280$ days), and they were placed 0.3-0.8, 1.0-1.5 and $0.8-1.5 \mathrm{~km}$ apart at ML, STSP and CER, respectively. The camera-traps were active $24 \mathrm{~h} \mathrm{~d}^{-1}$ and programmed to register the date and hour of each record. For most of the stations, we checked the traps monthly, and moved them to another site. Due to limited accessibility, in some sites at STSP and CER we left the camera for longer periods without checking them.

The abundance of oncilla was estimated at CER using capture-recapture closed population models of the CAPTURE 2.0 software using data only from June to September 2005. During this period, we monitored 29 trap stations placed 0.8 $1.5 \mathrm{~km}$ apart throughout 20 sample occasions. Each sample occasion was composed of 6 consecutive days to maximize capture probability (Отіs et al. 1978). Individual oncillas were identified by their unique spot and stripe patterns. Due to camera-trap availability, only 11 of the 29 stations were composed of two camera-traps facing each other to record simultaneously both sides of the individual to establish a link between patterns of both flanks. All records made in the single camera stations were from individuals that were also recorded at the stations with two camera traps, which suggests that we did not assign different sides of an individual to a different ID.

The Jack-knife estimator (model $\mathrm{M}_{\mathrm{h}}$ ) was used to estimate abundance, because it was considered more realistic since it allows for differences in individual probability of capture. Because the home range of the species is around $2.0 \mathrm{~km}^{2}$ (OLIVEIRA et al. 2010), we believe that with $0.8-1.5 \mathrm{~km}$ of distance among stations allowed us to have no areas inside the trapping station polygon with zero capture probability. Density was estimated by dividing the abundance by the effective sampled area, calculated as the polygon formed by all the trap stations and a buffer area. The buffer area was obtained by two indices: half of the mean maximum distances moved (HMMDM) and the mean maximum distances moved by each individual (MMDM). These distances moved by individuals are calculated only for animals captured in more than one station, considering the whole sampling period at CER.

The buffer width definition is still a controversial issue for density estimation studies. Although Karanth \& Nichols (1998) recommended the use of HMMDM based on a theoretical argument, empirical evidence based on comparisons of simultaneous camera trap and radiotelemetry studies demonstrated that in some cases HMMDM may underestimate the animal range (Soisalo \& Cavalcanti 2006), while in others it is indeed a fair approximation of the animal range (Di Bітетті et al. 2008). For better comparisons among studies, herein we provide estimates with both buffer widths.

Since cats are solitary and have wide variation in homerange sizes, we considered records obtained within 1-h intervals as independent (Gómez et al. 2005, Di BiтeTTi et al. 2006). Activity analyses were done using circular statistics, with the Oriana 2.0 software (Kovach Computing Services, UK). Activity patterns were compared for each species among areas using the F test of Mardia-Watson-Wheller (ZAR 1999). Data were grouped for each species in subsequent analyses whenever there were no differences in activity pattern among areas $(p>0.05)$. Rayleigh test (ZAR 1999) was used in order to verify if the distribution of the records for each species through the day was random. If the records were randomly distributed, the species was classified as cathemeral. Otherwise, we verified in the circular histograms at which period the records were concentrated and then we classified the species as nocturnal or diurnal. To verify the amplitude of the activity pattern of each species, we used circular variance and concentration of the data. High values of circular variance and low values of circular concentration indicated higher amplitude in the distribution of activity along the day.

\section{RESULTS}

Four cat species were recorded in the three sampled areas. Only the oncilla was recorded at all three sites, while margay and puma were recorded in the two high-relief forest areas (STSP e CER), and ocelot was recorded only in CER forest. Twelve oncillas were recorded through the whole sampling period at CER, two of them with a melanistic pelage. Melanistic individuals were also recognized through their subtle spots and strip patterns. Eight of the twelve individuals were recorded during the sampling period of density estimation in CER. The mean maximum distance moved was $4 \mathrm{~km}$ (range 1.53-8.58 
$\mathrm{km}, \mathrm{n}=5$ ). The trapping stations polygon covered $19.2 \mathrm{~km}^{2}$, which yielded an effective sampled area of $69,5 \mathrm{~km}^{2}$ or 137.5 $\mathrm{km}^{2}$ once applied the HMMDM and MMDM buffers, respectively. Total estimated abundance was $9 \pm 1.5$ individuals (mean $\pm \mathrm{SE}$ ), and the density was $7 \pm 1$ and $13 \pm 2$ individuals $/ 100 \mathrm{~km}^{2}$ (mean $\pm \mathrm{SE}$ ) considering the effective sampled area based on MMDM and HMMDM buffers, respectively.

Margay and puma showed similar activity patterns across the studied areas $(\mathrm{F}=2.04, \mathrm{p}<0.25$ and $\mathrm{F}=1.45, \mathrm{p}<0.32$, respectively). Ocelot, margay and puma did not show a random activity pattern over the day (Rayleigh $Z$ test; $\mathrm{p}<0.001$ ). In general, these three species were mostly nocturnal (Figs 1-3), but some differences can be noted. Ocelot was recorded almost exclusively at night (Fig. 2), margay was active mainly at night and at dawn (Fig. 1), and puma was recorded mostly at night, but with a relatively higher rate of diurnal activity (Fig. 3).

The activity patterns of the oncilla, on the other hand, differed within the study areas $(\mathrm{F}=14.54, \mathrm{p}<0.001)$ and con- trasted with the general nocturnal pattern of the other felid species. In the coastal salt marsh of ML, the oncilla did not show a random activity pattern through the day $(\mathrm{Z}=5.49$, $\mathrm{p}<0.001$ ), being more active during the night (Fig. 4). At STSP, although the activity was still nocturnal $(\mathrm{Z}=5.48, \mathrm{p}<0.001)$, records during daylight shifted from $15 \%$ to $38 \%$ (Fig. 5); and at CER, the oncilla was uniformly active during the day $(\mathrm{Z}=2.00, \mathrm{p}=0.14$, Fig. 6$)$. Concentration of activity was high for margay, ocelot and puma wherever they were present, but for oncilla only in ML (Fig. 7).

\section{DISCUSSION}

The oncilla showed lower densities when compared to other Neotropical small felid species, which may be due to the long distances of movement recorded in our study, resulting in a wide buffer and increased effective sampling area. Most of the ocelot density estimates, for instance, were higher than we
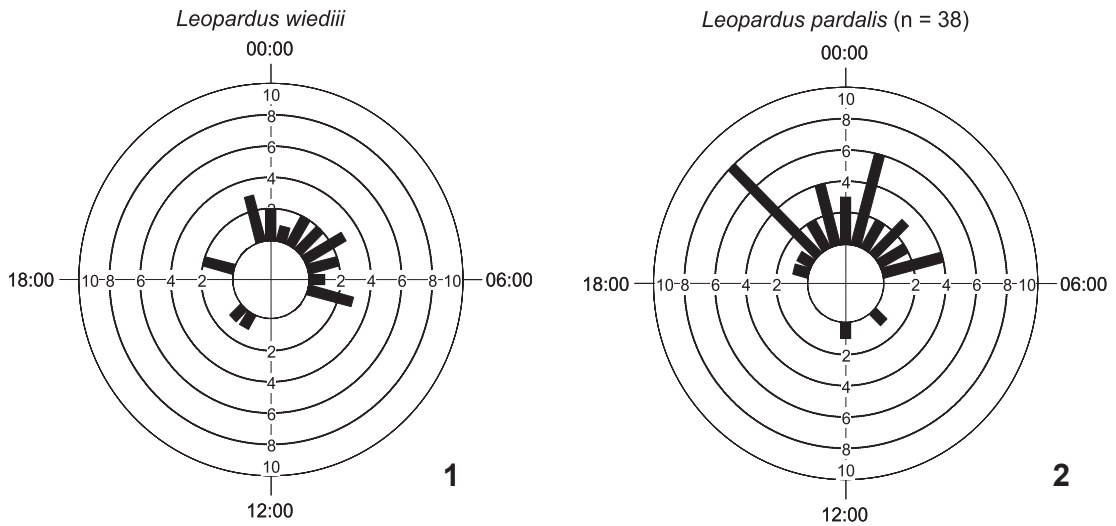

Leopardus tigrinus alone at $\mathrm{ML}(\mathrm{n}=26)$ 00:00

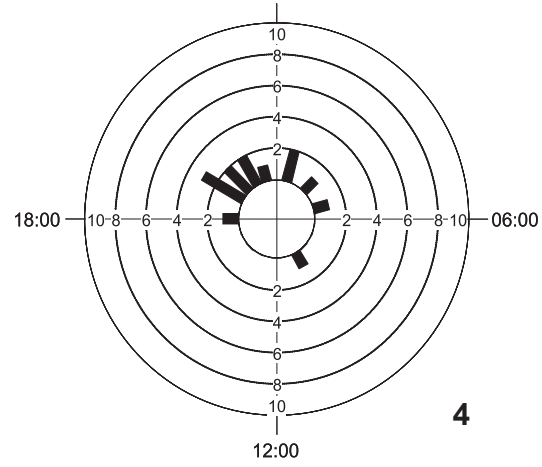

Leopardus tigrinus at STSP $(\mathrm{n}=78)$ sympatric with $P$. concolor and $L$. wiedii 00:00

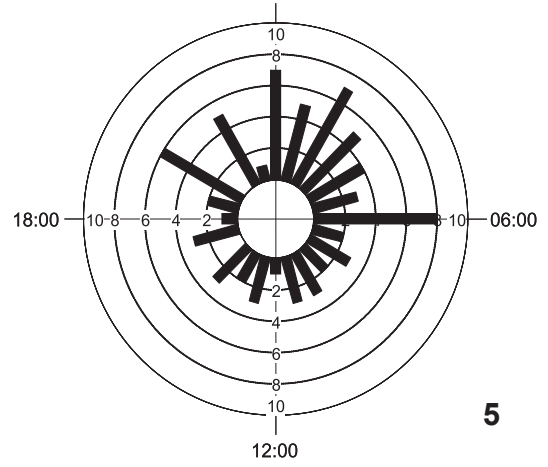

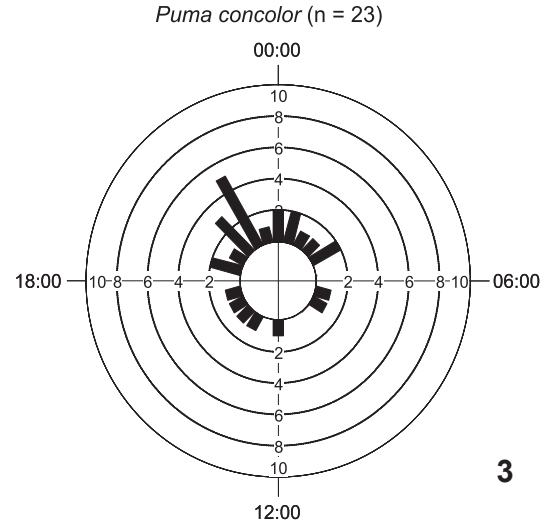

Leopardus tigrinus at CER $(n=65)$ sympatric with $P$. concolor, L. pardalis and L. wiedii

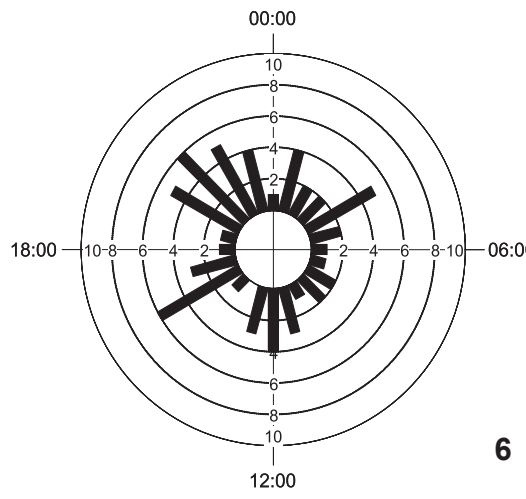

Figures1-6. Activity patterns of wild cats in the Atlantic Forest, southern Brazil. Above: activity patterns of Leopardus wiedii (1), Leopardus pardalis (2) and Puma concolor (3), respectively. Below: activity pattern of Leopardus tigrinus occurring at Lowland Atlantic Salt Marsh and Forests (4) or at two sites of Mountainous Evergreen Atlantic Forest (5 and 6). 


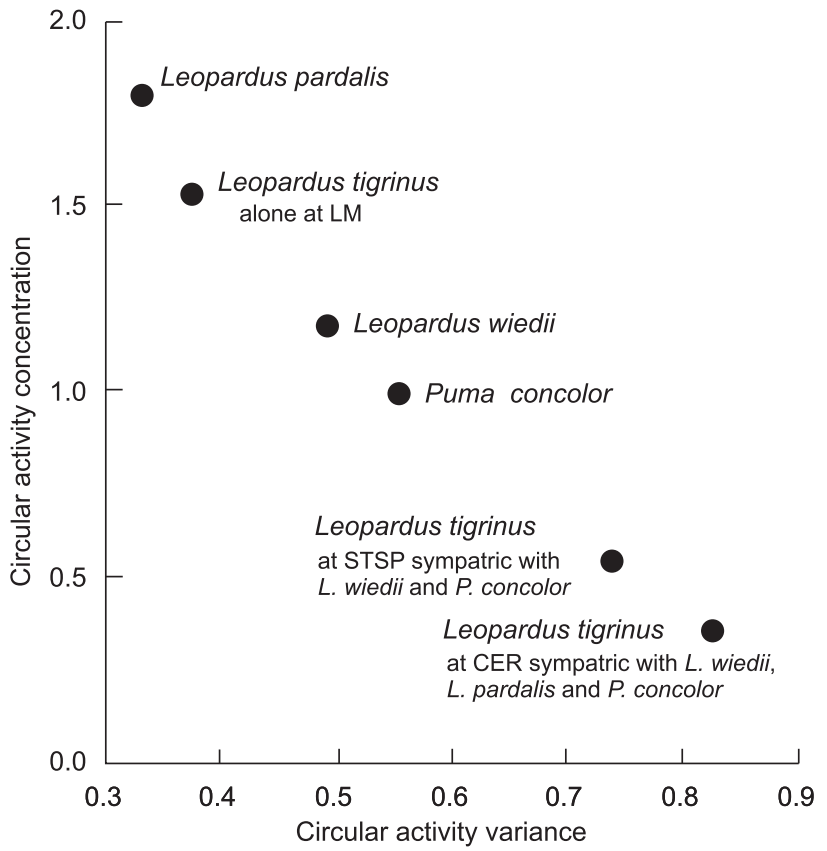

Figure 7. Circular activity concentration and circular activity variance of the wild cats in the Atlantic Forest of southern Brazil.

report for oncillas (9-160 ind./100 $\mathrm{km}^{2}$ in review of Di BiтeTTI et al. 2008), although lower ocelot densities have already been recorded in disturbed habitats, as pine forests (Dillon \& Kelly 2007).

The variation in the activity patterns of oncilla between sites may be explained both by habitat differences and the presence of larger cats that could trigger competitive intra-guild pressures over its behavior. Concerning habitat differences, ML landscape has forest patches interspersed with open areas dominated by herbaceous vegetation and shrubs that are also occupied by oncilla. CER and STSP are both covered by dense evergreen moist forest typical of the mountainous areas at low altitudes. These habitat differences could alter availability of shelter and, more importantly, the availability of prey items, determining the differences in activity. Although we have no information on whether abundance of potential diurnal preys differs between study areas, data from six diet studies of oncilla reviewed by Oliveira et al. (2010) - five of which were in hilly Atlantic Forest areas and another carried at $\mathrm{ML}-$, revealed similar diet composed mostly of nocturnal small rodents.

An alternative hypothesis to explain this behavioral change is the presence of sympatric larger cats. While margay, ocelot and puma were strictly or mainly nocturnal, similar to other studies (Oliveira 1994, Gómez et al. 2005), the oncilla was nocturnal only when it occurred with no other cats. On the other hand, it increased diurnal activity when other cats were present, becoming cathemeral. This pattern of activity flexibility of a subordinated species was also reported for Neotropical canids by Di Biтетті et al. (2009), who showed that the crabeating fox, Cerdocyon thous (Linnaeus, 1758), and the pampas fox, Lycalopex gymnocercus (Fischer, 1814) were both nocturnal in allopatry while in sympatry the smaller, pampas fox, showed activity peaks at the end of the night and around mid-day.

Exploitative competition is likely to be an important way by which these species affect each other. This would not be expected between oncilla and pumas because of their great differences in size and, hence, in the size of their prey. However, there is indeed a high diet overlap among the Neotropical small felids, including oncillas, margays and ocelots, despite no evidence of dietary release between species being demonstrated (Oliveira et al. 2010).

Cats are typically territorialists and the presence of one species can interfere with the occurrence of another, forcing the subordinate species to occupy poorer or marginal habitats or to be active in different hours (SUNQUIST \& SUNQUisT 1989, Palomares \& Caro 1999). Temporal segregation can play an important role in the mechanisms of co-occurrence between carnivore species that compete directly (CAROTHERS \& JAKSIC 1984), by which they avoid direct encounters and potential intra-guild predation that are rarely reported among Neotropical cats. As the smallest member of the Brazilian cat community, the oncilla is expected to play a subordinate role in direct interactions (PALOMARES \& CARo 1999). The change of the oncilla activity from nocturnal, when in allopatry, to cathemeral, when in simpatry with larger cats, could be a mechanism to decrease the activity overlap with their potential competitors. This time displacement of the oncilla to daylight periods could decrease the chance of interespecific encounters with margays, ocelots and pumas that presented mainly nocturnal activity. There are no documented predation evidences among the studied species and it is unlikely that medium-bodied predators like margays and ocelots could prey on oncillas. Thus, we believe many of interference relations among territorial carnivores can be shaped by defence and attack displays, scent marks or vocalizations, with no direct physical damage or death.

Shifts in activities were correlated with abundance estimations depicted by the rate of records of each species in each site. Assuming equal capturability of each species across the differences sites (as discussed by CARBone et al. 2001), our data support the idea that oncillas were more abundant at ML (4.5 record/100 trap-nights) in the absence of other cats, than at STSP and CER (3.0 and 1.6 records/100 trap-nights respectively), where 2 and 3 other cat species occurred, respectively. Correspondingly, Oliveira et al. (2010) describe a similar pattern across 12 studies in which ocelot was frequently the most abundant felid, while oncilla figured as the least abundant, except at those sites where ocelots were absent or rare.

Whether the differences in activity and abundance are more related to differences in habitat or intraguild competitive interactions are difficult to distinguish in this study as both 
factors covary. We here suggest that oncillas occupy a subordinate status in the South American small-felid guild, and the niche release by the absence of the larger cats (possibly margays and ocelots) in ML allowed the oncilla to occupy an optimal temporal niche that cannot be equally exploited in the presence of dominant competitors.

Density estimated at CER was as low as that reported for large felids like jaguars elsewhere. However, in ML we obtained the highest capture rate, even though it was also the lesser forested studied site. Recent studies have reported the presence of oncilla in remnants of the extremely degraded Atlantic Forest of southern and southeastern Brazil (FACURE \& GiaretTa 1996, Wang 2002, SRbek-Araújo \& Chiarello 2005). Along with the data reported herein, there is preliminary evidence that oncilla may persist in the degraded landscape of this extremely threatened hotspot. Should the landscape fragmentation result the loss of larger carnivores, remnant vertebrate communities will critically lack important ecological roles for its long-term maintenance (TеRвоRGH et al. 2001). In this scenario, oncilla may occupy a new trophic role, shifting both behavior and abundance and assuming the position of top predator of impoverished community. Finally, further studies could address important conservation cues of possible demographic responses of this threaten species to the lost of larger predators due to human driven landscape changes specially in relation to potential cascade effects over the small mammals community structure

\section{ACKNOWLEDGEMENTS}

We are very grateful to Russel Wid Coffin and FATMA for allowing field research at CER and STSP, respectively. We also thank Conservation International/Brazil, FAPESC and FUNPESQUISA/UFSC for logistical support. Appreciation is also due to Fidêncio Rohling and his family for field support. C.H.O. Salvador, V. Piacentini, F. Souza, H. Mozerle, and T. Maccarini helped us with field work in some expeditions. LGROS, FVBG and MAT were supported by CNPq and CAPES.

\section{LITERATURE CITED}

Carbone, C.; S. Christie; K. Conforti; T. Coulson; N. Franklin; J.R. Ginsberg; M. Griffiths; J. Holden; K. Kawanishi; M. Kinnaird; R. Laidlaw; A. Lynam; D.W. Macdonald; D. Martyr; C. Mcdougal; L. Nath; T.O. Obrien; J. Seidensticker; D.J.L. Smith; M. Sunquist; R. Tilson \& W.N. Wan Shahruddin. 2001. The use of photographic rates to estimate densities of tigers and other cryptic mammals. Animal Conservation 4: 75-79.

Carothers, J.H. \& F.M. Jaksic. 1984. Time as a niche difference: the role of interference competition. Oikos 42: 403-406.

Di Bitetti, M.S.; A. Paviolo \& C. De Angelo. 2006. Density, habitat use, and activity patterns of ocelots Leopardus pardalis in the Atlantic Forest of Misiones, Argentina. Journal of Zoology 270: 153-163.
Di Bitetti, M.S.; A. Paviolo; C. De Angelo \& Y.E. Di Blanco. 2008. Local and continental correlates of the abundance of a neotropical cat, the ocelot (Leopardus pardalis). Journal of Tropical Ecology 24: 189-200.

Di Bitetti, M.S.; Y.E. Di Blanco; J.A. Pereira; A. Paviolo \& I.J Perez. 2009. Time partitioning favors the coexistence of sympatric crab-eating foxes (Cerdocyon thous) and pampas foxes (Lycalopex Gymnocercus). Journal of Mammalogy 90: 479490.

Dillon, A.G. \& M.J. Kelly. 2007. Ocelot activity, trap success, and density in Belize: the impact of trap spacing and animal movement on density estimates. Oryx 41: 469-477.

Facure, K.G. \& A.A. GiaretTA. 1996. Food habits of carnivores in a coastal Atlantic forest of southeastern Brazil. Mammalia 60: 499-502.

Gómez, H.; R.B. Wallace; G. Ayala. \& R. Tejada. 2005. Dry season activity periods of some Amazonian mammals. Studies on Neotropical Fauna and Environment 40: 91-95.

Goulart, F.V.B.; N.C. Cáceres; M.E. Graipel; M.A. Tortato; I.R. Ghizoni \& L.G.R. Oliveira-Santos. 2009. Habitat selection by large mammals in a southern Brazilian Atlantic Forest. Mammalian Biology 74: 182-190.

KARANTH, K.U. \& J.D. Nichols. 1998. Estimation of tiger densities in India using photographic captures and recaptures. Ecology 79: 2852-2862.

OlIVEIRA, T.G. 1994. Neotropical cats: ecology and conservation. São Luís, Maranhão, Edufma, 220p.

Oliveira, T.G. \& K. Cassaro. 2005. Guia de Campo dos Felinos do Brasil. São Paulo, Instituto Pró-Carnívoros, Fundação Parque Zoológico de São Paulo, 80p.

Oliveira, T.G.; M.A. Tortato; L. Silveira; C.B. Kasper; F.D. Mazim; M. Lucherini; A.T. Jácomo; J.B.G. Soares; R.V. Marques \& M. SunquisT. 2010. Ocelot ecology and its effect on the smallfelid guild in the lowland Neotropics, p. 559-580. In: D. Macdonald \& A. Loveridge (Eds). The Biology and Conservation of Wild Felid. Oxford, Oxford University, $762 \mathrm{p}$.

Otis, D.L.; K.P. Burnham; G.C. White \& D. R. Anderson. 1978. Statistical inference from capture data on closed animal populations. Wildlife Monographs 62: 1-135.

Palomares, F. \& T.M. Caro. 1999. Interspecific killing among mammalian carnivores. American Naturalist 153: 492-508.

Silveira, L.; A.T.A. JÁcomo \& J.A.F. Diniz-Filho. 2003. Cameratrap, line transect census and track surveys: a comparative evaluation. Biological Conservation 114: 351-355.

Soisalo, M.K. \& S.M.C. Cavalcantr. 2006. Estimating the density of a jaguar population in the Brazilian Pantanal using camera-traps and capture-recapture sampling in combination with GPS radio-telemetry. Biological Conservation 129: 487-496.

Srbek-Araújo, A.C. \& Chiarello. A.G. 2005. Is camera-trapping an efficient method for surveying mammals in Neotropical forests? A study case in southeastern Brazil. Journal of Tro- 
pical Ecology 21: 121-125.

Sunquist, M.E. \& F.C. Sunquist. 1989. Ecological constraints on predation by large felids, p. 283-301. In: J.L. Gittleman (Ed.). Carnivore Behavior, Ecology and Evolution. Ithaca, Cornell University Press.

Terborgh, J.; L. Lopez; P.V. Nuñez; M. RaO; G. Shahabuddin; G. Orihuela; M. Riveros; R. Ascanio; G.H. Adler; T.D. Lambert \& L. Balbas. 2001. Ecological Meltdown in predator-free forest fragments. Science 294: 1923-1926.
Tortato, M.A. \& T.G. Oliveira. 2005. Ecology of the oncilla (Leopardus tigrinus) at Serra do Tabuleiro State Park, southern Brazil. Cat News 42: 28-30.

WANG, E. 2002. Diets of ocelots (Leopardus pardalis), margays (Leopardus wiedii), and oncillas (Leopardus tigrinus) in the Atlantic rainforest in southeast Brazil. Studies on Neotropical Fauna and Environment 37: 207-212.

ZAR, J.H. 1999. Biostatistical analysis. New Jersey, Prentice Hall, $662 p$.

Submitted: 29.XI.2011; Accepted: 12.IV.2012.

Editorial responsibility: Diego Astúa de Moraes 